\title{
Adherence to Medical Treatment and Its Determinants Among Adult Saudi Glaucoma Patients in Riyadh City
}

Asem Shadid ${ }^{1}$, Waleed Alrashed ${ }^{2}$, Abdulelah Bin Shihah ${ }^{3}$, Abdulrahman Alhomoud ${ }^{4}$, Mushref Alghamdi ${ }^{5}$, Abdulaziz Alturki ${ }^{1}$, Abdulaziz Shadid ${ }^{6}$, Essam Osman ${ }^{7}$, Alanoud Alfaris ${ }^{8}$, Rajiv Khandekar ${ }^{9}$

1. Medicine, Imam Mohammad Ibn Saud Islamic University, Riyadh, SAU 2. Ophthalmology, Imam Mohammad Ibn Saud Islamic University, Riyadh, SAU 3. Family Medicine, King Faisal Specialist Hospital and Research Center, Riyadh, SAU 4. Ophthalmology, King Khalid Eye Specialist Hospital, Riyadh, SAU 5. Internal Medicine, King Khalid University Hospital, Riyadh, SAU 6. Medicine, King Saud University, Riyadh, SAU 7. Ophthalmology, King Abdulaziz University Hospital, King Saud University, Riyadh, SAU 8. Epidemiology and Public Health, Imam Mohammad Ibn Saud Islamic University, Riyadh, SAU 9. Epidemiology and Public Health, King Khalid Eye Specialist Hospital, Riyadh, SAU

Corresponding author: Abdulaziz Alturki, p.a.y.99@hotmail.com

\section{Abstract}

\section{Background}

Glaucoma in adults is a leading eye disease that causes blindness. Its management is life long and both surgical and medical treatment options are available to manage this ailment. Patients and their caregiver's cooperation in instilling timely eye drops is crucial for the effective reduction of intraocular pressure (IOP) and by halting/delaying the progression of visual disabilities due to glaucoma. Periodic assessment and strict adherence to medical treatment has been found to be less than desired. It is influenced by the severity of the disease, the duration of the ailment, the number of eye drops being used, the literacy level, and the cost of medication. We present the adherence rate of topical medications and its determinants among adult Saudi glaucoma patients getting treated in 2017 in a tertiary eye center in Saudi Arabia.

\section{Methodology}

This cross-sectional survey was carried out from January to March 2017 at a tertiary eye hospital in Riyadh, Saudi Arabia. To undertake a cross-sectional study, we assumed that among 1300 patients visiting the eye department of a tertiary eye hospital, the level of non-adherence to glaucoma medication would be in $27 \%$ of glaucoma patients. To achieve a $95 \%$ confidence interval and an acceptable error margin of $5 \%$ for a survey, we needed to interview at least 253 participants.

\section{Results}

We interviewed 263 randomly selected glaucoma patients among 1236 patients visiting the eye department of the tertiary eye hospital in Riyadh, Saudi Arabia. Two-thirds of participants were school graduates, Saudi

Received 12/14/2019 Review began 01/11/2020 Review ended 01/31/2020 Published 02/02/2020

(c) Copyright 2020 Shadid et al. This is an open access article distributed under the terms of the Creative Commons Attribution License CC-BY 3.0., which permits unrestricted use, distribution, and reproduction in any medium, provided the original author and source are credited. nationals, and had undergone surgery for glaucoma in the past; perhaps only YAG laser peripheral iridotomy (PI). Less than half of the participants (43\%) had less than a one-year duration of glaucoma. The clientperceived subjective adherence rate to glaucoma medication was noted in 191/263 $=72.6 \%$ (95\% Confidence Interval $67.2-78.0$ ). Of the 263 glaucoma patients, 229 judiciously abided with their follow-up appointments with ophthalmologists. Thus, the compliance to follow-up for glaucoma treatment was $87.1 \%$ (95\% CI 83.0 91.1).

\section{Conclusion}

Our study with a large sample is perhaps the first one to assess compliance with medical treatment among adult Saudi glaucoma patients. The adherence rate for topical glaucoma medication measured using the subjective method was $72 \%$ among adult glaucoma patients. Adherence with the follow-up appointment with the glaucoma specialist was as high as $87 \%$. Adherence with medical treatment found in the present study versus the literature review suggested that despite different sets of barriers, the adherence rate in Saudi adult glaucoma patients noted in our study was high. Knowledge, beliefs, and attitude are known to affect the adherence rate. In our study, education level and relatives having glaucoma were not associated with the adherence rate. This indirectly suggests that knowledge about the use of medication in the treatment of glaucoma that is gained by patients had a limited influence on adherence in our glaucoma patients. Modes of dispersing knowledge to elderly glaucoma patients and their impact on the adherence rates of medications for glaucoma management need to be further studied.

Categories: Ophthalmology

Keywords: adult saudi glaucoma 


\section{Introduction}

Glaucoma in adults is a leading blinding eye disease [1]. Its management is life-long and both surgical and medical treatment options are available to manage this ailment [2]. However, both ophthalmologists and glaucoma patients prefer medical management. Safe and less frequent dosage of topical glaucoma medications are the main reason for this preference [3]. Patients and their caregiver's cooperation in instilling timely eye drops and the spacing between the drops are crucial for the effective reduction of intraocular pressure (IOP) and by halting/delaying the progression of visual disabilities due to glaucoma. Periodic assessment and strict adherence to medical treatment have been found to be less than desired [4-6]. It is influenced by the severity of the disease, the duration of the ailment, the number of eye drops being used, the literacy level, and the cost of medication [7-9]. To the best of our knowledge, a study of less than 100 Saudi glaucoma patients at a university hospital was carried out in 2012 [10]. In view of changes in glaucoma medications in the last 10 years, the client's acceptance among Saudi glaucoma patients is likely to change as compared to the past and is worthy of study.

We present the adherence rate of topical medications and its determinants among adult Saudi glaucoma patients getting treated in 2017 in a tertiary eye center in Saudi Arabia.

\section{Materials And Methods}

This cross-sectional survey was carried out from January to March 2017 at a tertiary eye hospital in Riyadh, Saudi Arabia. The institutional research board of the university approved this study. This being a surveybased study, written consent was waived. However, informed oral consent was obtained from all participants. The study was undertaken following the strict norms of the Helsinki declaration for research. Adult glaucoma patients declining to participate were excluded from the survey, and they were assured about their high-quality glaucoma care despite their refusal. The participant's personal identity was delinked from the result during the analysis.

To undertake a cross-sectional study, we assumed that among 1,300 patients visiting the eye department of a tertiary eye hospital, the level of non-adherence with glaucoma medication would be in $27 \%$ of glaucoma patients. To achieve a $95 \%$ confidence interval and an acceptable error margin of $5 \%$ for a survey, we needed to interview at least 253 participants.

Five medical students who were trained to undertake the interview of glaucoma patients were our field investigators. In our study, we defined non-adherence with glaucoma treatment based on client-perceived responses regarding questions on missing medication doses during the last two months. We also inquired judiciously about abiding with the appointments for follow-ups with glaucoma specialists.

The demographic information included age, gender, nationality, area of residence, education, status, and family history of glaucoma. Information about glaucoma-related barriers included the duration of glaucoma, past history of surgeries, and the number of glaucoma medications being used.

A pretested questionnaire in the Arabic language was used to enquire about adherence with glaucoma medication and possible risk factors for compliance. In view of the free cost of medication, as well as the ophthalmic services available in Saudi Arabia, we did not include cost as one of the barriers to adherence.

The data were transferred from forms to a Microsoft Excel spreadsheet (Microsoft Corporation, Redmond, Washington). Based on the day of the interview and the date of birth, age in years was calculated. The date of the last follow-up and the date of glaucoma diagnosis was used to estimate the duration of glaucoma treatment. It was further categorized as within one year, one to five years, and more than five years. We transferred the data in spreadsheet form to Statistical Package for Social Sciences (SPSS 23; IBM Corp., Armonk, NY). Frequency distribution and percentage proportion was the method of presentation of qualitative variables. For quantitative variables such as age, we plotted the distribution and if it was normal, we calculated the mean and standard deviation. In cases of uneven distribution, we presented the median and $25 \%$ quartile values. To compare the adherence rate among subgroups, we used $2 \times 2$ tables and estimated the odd's ratio, $95 \%$ confidence interval, and two-sided p-value. If $\mathrm{p}$ was less than 0.05 , we considered it statistically significant.

\section{Results}

The profile of the participants is given in Table 1. Two-thirds were school graduates, Saudi nationals, and had undergone surgery for glaucoma in the past (e.g., YAG laser peripheral iridotomy (PI)). Most (57\%) had glaucoma for more than one year. 


\section{Cureus}

\begin{tabular}{|c|c|c|c|}
\hline \multicolumn{2}{|l|}{ Variables } & Number & Percentage \\
\hline Gender & Male; Female & $152 ; 111$ & $57.8 ; 42.2$ \\
\hline Education & $\begin{array}{l}\text { Read and write less than Bachelor; Bachelor; More than } \\
\text { Bachelor }\end{array}$ & 156;66;39; 2 & $\begin{array}{l}59.3 ; 25.1 ; 14.8 ; \\
0.8\end{array}$ \\
\hline Nationality & Saudi; Non-Saudi & $202 ; 61$ & 76.8; 23.2 \\
\hline Resident & Riyadh; Outside Riyadh & $177 ; 86$ & $67.3 ; 32.7$ \\
\hline Glaucoma diagnosed & Within 1 year; 1 to 5 years; More than 5 years & $115 ; 96 ; 52$ & $43.7 ; 36.5 ; 19.8$ \\
\hline Glaucoma being treated & Yes; No & $256 ; 7$ & $97.3 ; 6.7$ \\
\hline $\begin{array}{l}\text { Number of glaucoma medications } \\
\text { prescribed }\end{array}$ & ; $2 ; 3$; More than 3 & $\begin{array}{l}54 ; 141 ; 54 ; \\
14\end{array}$ & $\begin{array}{l}20.5 ; 53.6 ; 20.5 ; \\
5.3\end{array}$ \\
\hline Glaucoma surgery in the past (including PI) & Yes; No & $200 ; 63$ & $76.0 ; 24.0$ \\
\hline Glaucoma in relatives & Yes; No & $141 ; 122$ & $53.6 ; 46.4$ \\
\hline Age (years) & Mean; SDV & .6; 14 & \\
\hline
\end{tabular}

TABLE 1: Profile of adult glaucoma patients being treated with glaucoma medications

The client-perceived subjective adherence rate to glaucoma medication was noted in 191/263 $=72.6 \%$ (95\% confidence interval 67.2-78.0). Of the 263 glaucoma patients, 229 carefully attended follow-up appointments with ophthalmologists. Thus, the compliance to follow-up for glaucoma treatment was $87.1 \%$ (95\% CI 83.0 91.1).

The demographic details and risk factors were associated with glaucoma medication adherence (Table 2). Glaucoma patients with a shorter duration of the disease had significantly worse compliance with medical treatment than those with a longer duration of glaucoma. Other factors were not significantly associated with adherence. The adherence rate in this present study was compared to other studies in the literature (Table 3). 


\section{Cureus}

\begin{tabular}{|c|c|c|c|c|c|c|}
\hline \multirow{2}{*}{ Determinants } & & \multicolumn{2}{|c|}{ Adherence ( $\mathrm{N}=191)$} & \multicolumn{2}{|c|}{$\begin{array}{l}\text { Non-adherence }(\mathrm{N}= \\
\text { 72) }\end{array}$} & \multirow[t]{2}{*}{ Validation } \\
\hline & & Number & Percentage & Number & Percentage & \\
\hline Gender & Male; Female & $107 ; 84$ & $70.4 ; 75.7$ & $45 ; 27$ & $29.6 ; 24.3$ & $\begin{array}{l}\mathrm{OR}=0.76(95 \% \mathrm{Cl} 0.4- \\
1.3), \mathrm{p}=0.3\end{array}$ \\
\hline Education & School graduate; Higher education & $109 ; 82$ & $57.1 ; 42.9$ & $47 ; 25$ & $65.3 ; 34.7$ & $\begin{array}{l}\mathrm{OR}=0.7(95 \% \mathrm{Cl} 0.4-1.2), \\
\mathrm{p}=0.2\end{array}$ \\
\hline $\begin{array}{l}\text { History of glaucoma } \\
\text { surgery }\end{array}$ & Yes; No & $146 ; 45$ & $76.4 ; 23.6$ & $54 ; 18$ & $75 ; 25$ & $\begin{array}{l}\text { OR }=1.1(95 \% \text { Cl } 0.6-2.0) \\
p=0.8\end{array}$ \\
\hline Residence & Riyadh; Outside Riyadh & $129 ; 62$ & $67.5 ; 32.5$ & $48 ; 24$ & $66.7 ; 33.3$ & $\begin{array}{l}\mathrm{OR}=1.0(95 \% \mathrm{Cl} 0.6-1.9) \\
\mathrm{p}=0.9\end{array}$ \\
\hline $\begin{array}{l}\text { Using glaucoma } \\
\text { medications }\end{array}$ & 1 to $2 ; 3$ and more & $140 ; 51$ & $73.3 ; 26.7$ & $55 ; 17$ & $76.4 ; 23.6$ & $\begin{array}{l}\text { OR }=0.8(95 \% \text { Cl } 0.5-1.6), \\
p=0.6\end{array}$ \\
\hline $\begin{array}{l}\text { Relative suffering from } \\
\text { glaucoma }\end{array}$ & Yes; No & $97 ; 94$ & $50.8 ; 49.2$ & $44 ; 28$ & $61.1 ; 38.9$ & $\begin{array}{l}\mathrm{OR}=0.7(95 \% \mathrm{Cl} 0.4-1.1), \\
\mathrm{p}=0.1\end{array}$ \\
\hline Age & Mean SDV & \multicolumn{2}{|l|}{$61.3 ; 14.9$} & \multicolumn{2}{|l|}{$62.4 ; 12.2$} & $p=0.6$ \\
\hline Duration of glaucoma & $\begin{array}{l}\text { Within } 1 \text { year; } 1 \text { to } 5 \text { years; More than } \\
5 \text { years }\end{array}$ & $\begin{array}{l}69 ; 75 \\
47\end{array}$ & $\begin{array}{l}36.1 ; 39.3 \\
24.6\end{array}$ & $46 ; 215$ & $\begin{array}{l}63.9 ; 29.2 ; \\
6.9\end{array}$ & $X^{2}=17.8, d f^{*}=3, P<0.001$ \\
\hline
\end{tabular}

TABLE 2: Adherence to the glaucoma medication among adult Saudi patients and their statistics

\begin{tabular}{|c|c|c|c|c|c|c|}
\hline & Author & Year & Sample size & Adherence rate & Notes & Reference \\
\hline 1 & Khandekar R & 2005 & 105 & $25 \%$ compliance & Poor KAP as a cause & 9 \\
\hline 2 & Osman EA & 2016 & 108 & $81.6 \%$ & Duration of medication and barrier & 10 \\
\hline 3 & Masouri K & 2011 & 200 & $81 \%$ & Glaucoma patients in Switzerland & 12 \\
\hline 4 & Mehri T & 2016 & 359 & $42.6 \%$ & Cost, education level and barriers & 13 \\
\hline 5 & Newman Casey & 2015 & 1234 & $23 \%$ after 4 years & Duration, age and cost barriers & 11 \\
\hline 6 & Cohen Costel O & 2014 & 738 & $71 \%$ & Duration, age, and barriers & 14 \\
\hline 7 & Boland MV & 2014 & 407 & $82.8 \%$ & Objective method, 3 months after the start of medication & 15 \\
\hline 8 & Lunnela J & 2011 & 249 & $67 \%$ & Finnish glaucoma patients & 16 \\
\hline 9 & Movahedinejad T & 2016 & 130 & $34 \%$ & Education, rural patients barrier & 17 \\
\hline 10 & Jiang $\mathrm{H}$ & 2017 & 156 & 53.2 & Complex medications barrier & 18 \\
\hline
\end{tabular}

TABLE 3: Adherence to glaucoma medication among adult Saudi glaucoma patients compared to other studies.

\section{Discussion}

Our study, which has a large sample, is perhaps one of the first studies to assess compliance with medical treatment among adult Saudi glaucoma patients. The adherence rate for topical glaucoma medication measured in the subjective method was $72 \%$ among adult glaucoma patients. Adherence with the follow-up appointment with the glaucoma specialist was as high as $87 \%$. Those with less than a one-year duration of glaucoma treatment had a significantly poorer adherence rate with glaucoma medication usage as compared to patients with a longer duration of ailment.

Adult glaucoma patients that we studied are unique, as ophthalmic services and medications to Saudi 
residents is available free of cost or the cost is reimbursed by the insurance company in most cases. Thus, the cost of medication is less likely a barrier resulting in non-adherence with the medical treatment of glaucoma in this population.

Adherence with medical treatment found in the present study versus the literature suggested that despite different sets of barriers, the adherence rate in Saudi adult glaucoma patients noted in our study was high $[10,11-18]$. It was as low as $25 \%$ in Oman and as high as $81 \%$ in Switzerland. Different methods (subjective and objective methods of assessment and the variation of barriers in different countries could explain this wide variation in adherence rate). Identifying the barriers and addressing them could improve the adherence rate for taking prescribed glaucoma medications.

A shorter duration of glaucoma was significantly associated with the low adherence rate in our study. This was noted in a study where compliance was studied in the first and fourth years [11]. Cost implications and the human behavior of lethargy after some time could be the reason for poor adherence with glaucoma medications. In spite of having free access to medication and ophthalmic services, the non-adherence of $13 \%$ of glaucoma patients needs to be reviewed in further detail to address them.

The number of medications is a representation of the complexity of the glaucoma medication regimen. In our study, most cases were using one or two medications to manage their glaucoma. Newer, long-lasting medications that need to be instilled once a day, although costly, are free for Saudi patients, and this could explain the differential adherence found in our study and other studies [19-20].

Although the adherence rate of glaucoma medication was better in males as compared to females in our study, the element of chance observation cannot be ruled out. Gender was not a risk factor for adherence in China [18].

Age was not associated with the adherence rate in our study. However, researchers from Iran noted it as a significant risk factor [17]. Perhaps one of the barriers affecting older patients is cost, as seen in another study but not in Saudi Arabia. Having free-of-cost health services for older Saudi patients with a mean age of 62 as compared to glaucoma patients in Iran (mean 53) could explain age being a differential barrier for adherence.

A number of demographic and social factors have been associated with adherence to glaucoma medications [21]. In western countries, the elderly population is living in isolation and not having family support in contrast to Saudi society; therefore, the self-reliance of doses and instillation of eye drops could be an important difference, which we did not find significantly affecting the adherence rate in our study.

Knowledge, beliefs, and attitude is known to affect the adherence rate. In our study, the education level and a relative having glaucoma were not associated with the adherence rate. This indirectly suggests that knowledge about the use of medication in the treatment of glaucoma, which is gained by patients, had a limited influence on adherence in our glaucoma patients. Modes of dispersing knowledge to elderly glaucoma patients and their impact on adherence rates to medications for glaucoma management need to be further studied.

We had a few limitations to our study. Self-reporting on adherence was used as a method used similarly in many other studies. However, the objective method, a more reliable mode of measuring the adherence rate, has been tested for a short duration (three months) of glaucoma treatment [15,22]. It could be better to determine the negative effect of non-compliance on the progression of glaucoma. But the practical implications of using such a method in many cases where medications are to be used lifelong are questionable. There are a number of subcomponents of non-compliance to the medical treatment of chronic diseases [9]. We assessed only self-reported misses of doses and ophthalmic appointments. This could have resulted in unintentionally underestimating nonadherence.

The adherence rate in this present study was compared with other studies in the literature (Table 4). 


\section{Cureus}

\begin{tabular}{|c|c|c|c|c|c|c|}
\hline & Author & Year & Sample size & Adherence rate & Notes & Reference \\
\hline 1 & Khandekar R & 2005 & 105 & $25 \%$ compliance & Poor KAP as a cause & 9 \\
\hline 2 & Osman EA & 2016 & 108 & $81.6 \%$ & Duration of medication and barrier & 10 \\
\hline 3 & Masouri K & 2011 & 200 & $81 \%$ & Glaucoma patients in Switzerland & 12 \\
\hline 4 & Mehri T & 2016 & 359 & $42.6 \%$ & Cost, education level and barriers & 13 \\
\hline 5 & Newman Casey & 2015 & 1234 & $23 \%$ after 4 years & Duration, age, and cost barriers & 11 \\
\hline 6 & Cohen Costel O & 2014 & 738 & $71 \%$ & Duration, age, and barriers & 14 \\
\hline 7 & Boland MV & 2014 & 407 & $82.8 \%$ & Objective method, 3 months after the start of medication & 15 \\
\hline 8 & Lunnela J & 2011 & 249 & $67 \%$ & Finish glaucoma patients & 16 \\
\hline 9 & Movahedinejad T & 2016 & 130 & $34 \%$ & Education, rural patients barrier & 17 \\
\hline 10 & Jiang $\mathrm{H}$ & 2017 & 156 & 53.2 & Complex medications barrier & 18 \\
\hline
\end{tabular}

TABLE 4: Adherence with glaucoma medication among adult Saudi glaucoma patients as compared to other studies

\section{Conclusions}

In conclusion, adherence is influenced by the severity of the disease, duration of the ailment, number of eye drops being used, literacy level, and cost of medication. The adherence rate for topical glaucoma medication was $72 \%$ among adult glaucoma patients, and the adherence to follow-up appointments with a glaucoma specialist was as high as $87 \%$. The adherence rate in adult Saudi glaucoma patients was high, which is encouraging; however, a better assessment method than self-reporting is recommended to confirm the findings. The use of modern tools for better patient counseling and the addressing of identified barriers could make further inroads in delaying severe blinding complications of glaucoma thus affecting the quality of life. More work is needed to study knowledge distribution to elderly glaucoma patients and its impact on medication adherence rates.

\section{Additional Information}

\section{Disclosures}

Human subjects: Consent was obtained by all participants in this study. Animal subjects: All authors have confirmed that this study did not involve animal subjects or tissue. Conflicts of interest: In compliance with the ICMJE uniform disclosure form, all authors declare the following: Payment/services info: All authors have declared that no financial support was received from any organization for the submitted work. Financial relationships: All authors have declared that they have no financial relationships at present or within the previous three years with any organizations that might have an interest in the submitted work. Other relationships: All authors have declared that there are no other relationships or activities that could appear to have influenced the submitted work.

\section{References}

1. Pascolini D, Mariotti SP: Global estimates of visual impairment: 2010. Br J Ophthalmol. 2012, 96:614-618. 10.1136/bjophthalmol-2011-300539

2. Prum BE Jr., Rosenberg LF, Gedde SJ, et al.: Primary Open Angle Glaucoma PPP - 2015 . 2015.

3. Shaikh Y, Yu F, Coleman AL: Burden of undetected and untreated glaucoma in the United States . Am J Ophthalmol. 2014, 158:1121-1129. 10.1016/j.ajo.2014.08.023

4. Harasymowycz P, Birt C, Gooi P, et al.: Medical management of glaucoma in the 21st century from a Canadian perspective. J Ophthalmol. 2016, 2016:6509809. 10.1155/2016/6509809

5. Hark LA, Leiby BE, Waisbourd M, et al.: Adherence to follow-up recommendations among individuals in the Philadelphia Glaucoma Detection and Treatment Project. J Glaucoma. 2017, 26:697-701. 10.1097/IJG.0000000000000716

6. Kim CY, Park KH, Ahn J, et al.: Treatment patterns and medication adherence of patients with glaucoma in South Korea. Br J Ophthalmol. 2017, 101:801-807. 10.1136/bjophthalmol-2016-308505

7. Fudemberg SJ, Lee B, Waisbourd M: Factors contributing to nonadherence to follow-up appointments in a resident glaucoma clinic versus primary eye care clinic. Patient Prefer Adherence. 2016, 10:19-25.

8. Sheer R, Bunniran S, Uribe C, Fiscella RG, Patel VD, Chandwani HS: Predictors of nonadherence to topical intraocular pressure reduction medications among Medicare members: a claims-based retrospective cohort study. J Manag Care Spec Pharm. 2016, 22:808-817. 10.18553/jmcp.2016.22.7.808 
9. Khandekar R, El-Sayed Shama M, Mohammed AJ: Noncompliance with medical treatment among glaucoma patients in Oman-a cross-sectional descriptive study. Ophthalmic Epidemiol. 2005, 12:303-309. 10.1080/09286580500224602

10. Osman EA, Alqarni BA, AlHasani SS, Al Harbi SS, Gikandi PW, Mousa A: Compliance of glaucoma patients to ocular hypotensive medications among the Saudi population. J Ocul Pharmacol Ther. 2016, 32:50-54. 10.1089/jop.2015.0052

11. Newman-Casey PA, Robin AL, Blachley T, Farris K, Heisler M, Resnicow K, Lee PP: The most common barriers to glaucoma medication adherence: a cross-sectional survey. Ophthalmology. 2015, 122:1308-1316. 10.1016/j.ophtha.2015.03.026

12. Mansouri K, Iliev ME, Rohrer K, Shaarawy T: Compliance and knowledge about glaucoma in patients at tertiary glaucoma units. Int Ophthalmol. 2011, 31:369-376.

13. Mehari T, Giorgis AT, Shibeshi W: Level of adherence to ocular hypotensive agents and its determinant factors among glaucoma patients in Menelik II Referral Hospital, Ethiopia. BMC Ophthalmol. 2016, 16:131.

14. Cohen Castel O, Keinan-Boker L, Geyer O, Milman U, Karkabi K: Factors associated with adherence to glaucoma pharmacotherapy in the primary care setting. Fam Pract. 2014, 31:453-461. 10.1093/fampra/cmu031

15. Boland MV, Chang DS, Frazier T, Plyler R, Friedman DS: Electronic monitoring to assess adherence with once-daily glaucoma medications and risk factors for nonadherence. The automated dosing reminder study. JAMA Ophthalmol. 2014, 132:838-844. 10.1001/jamaophthalmol.2014.856

16. Lunnela J, Kääriäinen M, Kyngäs H: Adherence of Finnish people with glaucoma to treatment plans and connected factors. Int J Circumpolar Health. 2011, 70:79-89. 10.3402/ijch.v70i1.17796

17. Movahedinejad T, Adib-Hajbaghery M: Adherence to treatment in patients with open-angle glaucoma and its related factors. Electron Physician. 2016, 8:2954-2961.

18. Jiang H, Zhao L, Yang L, Cai HY: Relationships among illness perceptions, medication beliefs and medication adherence in primary angle closure glaucoma patients [Article in Chinese]. Zhonghua Yan Ke Za Zhi. 2017, 53:109-114. 10.3760/cma.j.issn.0412-4081.2017.02.008

19. Covert D, Robin AL: Adjunctive glaucoma therapy use associated with travoprost, bimatoprost, and latanoprost. Curr Med Res Opin. 2006, 22:971-976. 10.1185/030079906X104777

20. Rees G, Leong O, Crowston JG, Lamoureux EL: Intentional and unintentional nonadherence to ocular hypotensive treatment in patients with glaucoma. Ophthalmology. 2010, 117:903-908. 10.1016/j.ophtha.2009.10.038

21. Cook PF, Schmiege SJ, Mansberger SL, Kammer J, Fitzgerald T, Kahook MY: Predictors of adherence to glaucoma treatment in a multisite study. Ann Behav Med. 2015, 49:29-39. 10.1007/s12160-014-9641-8

22. Hermann MM, Ustündag C, Diestelhorst M: Electronic compliance monitoring of topical treatment after ophthalmic surgery. Int Ophthalmol. 2010, 30:385-390. 